\title{
ANALISIS PEDAGOGICAL CONTENT KNOWLEDGE (PCK) TERHADAP BUKU GURU SD KURIKULUM 2013
}

\author{
Gaguk Resbiantoro \\ gaguk.resbiantoro@stkippgritulungagung.ac.id \\ STKIP PGRI Tulungagung
}

\begin{abstract}
ABSTRAK
Analisis buku pegangan guru SD dalam implementasi kurikulum 2013 perlu dilakukan karena buku ini menjadi acuan guru dalam mengajar. Guru SD harus menguasai konten materi dan cara penyampaian (pengajarannya) kepada peserta didik atau yang dikenal sebagai PCK (Pedagogical Content Knowledge). Buku pegangan guru harus sesuai dengan kaidah-kaidah PCK. Penelitian ini merupakan penelitian deskriptif yang bertujuan untuk memperoleh informasi mengenai ruang lingkup Pedagogical Content Knowledge pada buku pegangan guru SD. Populasi pada penelitian ini adalah semua bab pada buku pegangan guru SD yang digunakan dalam implementasi kurikulum 2013. Sedangkan sampel pada penelitian ini adalah beberapa bab pada buku yang dianalisis, diambil sebanyak $20 \%$ dengan cara purposive random dari sebuah buku yang menjadi acuan mengajar SD yang digunakan dalam implementasi kurikulum 2013, khususnya muatan IPA. Hal tersebut atas pertimbangan bahwa karakteristik materi IPA sangat sesuai dengan teori konstruktivisme anak SD dan pendekatan saintifik. Data dijaring dengan lembar observasi berupa instrumen evaluasi buku guru yang berisi perpaduan indikator PCK dari lima komponen PCK yang dikembangkan oleh Magnusson et al. dalam Newsome dan Lederman (2002) dan instrumen yang telah dikembangkan Swanepoel (2010). Identifikasi dilakukan pada dua sampel buku guru SD kurikulum 2013 pada satu sub tema. Rata-rata prosentase masing-masing sub komponen PCK dalam buku guru SD kurikulum 2013 yaitu capaian pembelajaran 82\%, pengetahuan inti 44\%, hakekat ilmu pengetahuan $52 \%$, kegiatan pembelajaran $74 \%$, penilaian $50 \%$, contoh dan penjelasan $67 \%$, kerangka metakognisi $58 \%$, perbedaan perlakuan siswa $58 \%$, serta pemberian motivasi pada siswa 79\%. Sub komponen Content Knowledge perlu dilengkapi tentang pengetahuan miskonsepsi dan pengetahuan tambahan. Sedangkan sub komponen Pedagogical Knowledge perlu dilengkapi tentang kelengkapan penilaian dan kerangka metakognisi. Beberapa permasalahan tersebut dapat menjadi pertimbangan untuk penelitian lanjutan.
\end{abstract}

Kata kunci: buku pegangan guru, kurikulum 2013, pedagogical content knowledge

\section{PENDAHULUAN}

Fensham (2008) menyatakan ada 11 isu penting dalam kebijakan pendidikan sains. Isu tersebut mencakup 3 isu berkaitan tentang kebijakan pemerintah, 1 isu berkaitan tentang siswa dan latar belakangnya, dan 7 isu berkaitan dengan kualitas guru. Isu yang berkaitan dengan guru adalah: (1) how technology relates to science in education (cara untuk mengaitkan teknologi dengan pendidikan sains), (2) the nature of science and inquiry (hakikat sains dan inkuiri), (3) quality of learning in science (kualitas pembelajaran sains), (4) the use of ICT in science and technology education (penggunaan ICT dalam pembelajaran sains), (5) development of relevant and effective assessment in science education (pengembangan asesmen yang tepat dan efektif untuk pendidikan sains), (6) science education in the primary or elementary years (pendidikan sains mulai dari sekolah dasar), (7) professional development of science teachers (meningkatkan profesionalisme guru). Guru lebih disoroti dalam isu global pendidikan, artinya guru merupakan faktor kunci dalam pembelajaran sains, walaupun bukanlah faktor satu-satunya. 
Guru menjadi salah satu penentu mutu pendidikan nasional karena perannya yang sangat penting. Pemerintah menjamin mutu pendidikan dengan menentukan standar nasional pendidikan yang dituangkan dalam PP No. 19 Tahun 2005. Berdasarkan PP tersebut, pendidik harus memiliki kualifikasi akademik dan kompetensi sebagai agen pembelajaran, sehat jasmani dan rohani, serta memiliki kemampuan dalam mewujudkan tujuan pendidikan nasional. Selanjutnya, kompetensi sebagai agen pembelajaran pada tingkat pendidikan dasar, pendidikan menengah serta pendidikan anak usia dini meliputi kompetensi pedagogi, profesional, kepribadian, dan sosial. Keempat aspek kompetensi tersebut juga tertuang pada UU nomor 14 Tahun 2005 tentang Guru dan Dosen. Pasal 39 UU nomor 20 Tahun 2003 mendefinisikan bahwa guru merupakan tenaga profesional yang bertugas merencanakan, melaksanakan, menilai proses pembelajaran, melaksanakan pembimbingan dan pelatihan, serta melaksanakan penelitian dan pengabdian kepada masyarakat, khususnya pendidik pada perguruan tinggi.

Kualitas guru sangat berpengaruh terhadap kualitas pendidikan. Oleh karena itu, pembinaan terhadap guru menuju profesionalisme terus dilakukan pemerintah Indonesia. Salah satu upaya yang dilakukan pemerintah adalah menyediakan buku pegangan guru dalam implementasi kurikulum 2013. Buku pegangan guru SD mestinya memenuhi kaidah-kaidah Pedagogical Content Knowledge (PCK), yaitu berisi konten materi dan strategi pembelajarannya.. Oleh karena itu, penelitian ini bertujuan untuk menganalisis aspek PCK dalam buku pegangan guru SD dalam implementasi kurikulum 2013.

\section{KAJIAN PUSTAKA}

PCK (Pedagogical Content Knowledge) merupakan dimensi pengetahuan profesional yang penting bagi guru dan calon guru (Shulman, 1986). PCK terdiri dari pengetahuan pedagogi dan pengetahuan materi atau dapat dipahami sebagai pengetahuan tentang materi dan cara mengajarkannya. PCK meliputi aspek-aspek yang menunjang tugas guru untuk melaksanakan pembelajaran. Adapun aspek-aspek tersebut menurut Shulman (1986) yaitu ide, analisa, ilustrasi, contoh-contoh, penjelasan dengan demonstrasi, serta perumusan pokok materi. Pengetahuan aspek pedagogi juga meliputi suatu pemahaman tentang penyebab kesulitan tentang topik materi pelajaran bagi siswa.

PCK dapat diartikan sebagai kemampuan seseorang dalam mentransfer pengetahuan ke orang lain. Lebih rinci lagi, Shulman (1986) menyatakan bahwa PCK meliputi cara-cara yang dapat mewakili atau merumuskan materi sehingga membuat orang lain paham, pemahaman tentang sebab suatu materi pembelajaran topik tertentu sulit atau mudah (tingkat kesulitan materi), pemahaman bahwa siswa dengan berbagai usia dan latar belakang dibawa kepadanya untuk diajarkan topik pembelajaran tertentu (Turnuklu \& Yesildere, 2007). Pernyataan tersebut berarti PCK adalah cara merepresentasikan dan merumuskan suatu subyek sehingga materi itu dapat dipahami secara menyeluruh. PCK berhubungan dengan cara para guru menghubungkan pengetahuan materi yang diajarkan dengan pengetahuan tentang cara mengajar dan alasan tentang memadukan pengetahuan materi menjadi bagian dari proses pembelajaran (Cochran, 1993).

PCK mencakup kegiatan inti pengajaran, pembelajaran, kurikulum, penilaian, dan pelaporan yaitu yang mendukung kegiatan belajar siswa dan hubungan antara kurikulum, penilaian, dan pedagogi (Mishra \& Koehler, 2009). Shulman dan Cochran, et al., (1993) menyatakan bahwa PCK meliputi pemahaman tentang apa yang dapat dilakukan dalam pembelajaran suatu konsep spesifik sesuai tingkat kesulitannya terhadap para siswa (dengan berbagai umur dan latar belakang) yang mempunyai konsepsi dan pengetahuan awal agar mereka belajar.

PCK merupakan salah satu pengetahuan yang harus dimiliki oleh guru dan calon guru. PCK merupakan pengetahuan tentang materi yang diajarkan dengan cara mengajarkannya (Shulman, 1987). 
PCK meliputi aspek-aspek yang sangat berhubungan dengan kegiatan mengajar para guru. Adapun aspek-aspek tersebut yaitu ide, analisa, ilustrasi, contoh-contoh, penjelasan, demonstrasi, dan perumusan pokok materi (Shulman, 1986). Pengetahuan pedagogi juga meliputi suatu pemahaman tentang apa yang membuat topik materi pelajaran menjadi sulit atau mudah. Konsep PCK didasarkan pada teori tentang pengetahuan pedagogi dan kemampuan untuk menunjukan pentingnya pemahaman pengetahuan tertentu dalam menerangkan pokok materi di dalam pembelajaran (Shulman, 1986).

Salah satu faktor yang memungkinkan untuk meningkatkan keefektifan guru adalah memperkuat PCK mereka (Williams \& Lockley, 2012), yaitu suatu perpaduan antara pedagogical knowledge dan content knowledge yang berkembang setiap waktu dari pengalaman, sehingga menghasilkan guru profesional. PCK adalah kemampuan yang menyajikan tentang cara memotivasi, yang berkembang terus menerus melalui pengalaman tentang bagaimana mengajar konten materi tertentu dengan suatu cara agar pemahaman siswa tercapai (Loughran, Berry, \& Mulhall, 2012).

Model PCK guru yang diusulkan oleh Magnusson, Krajcik, \& Borko (2002) merupakan pengembangan dari model PCK yang telah diusulkan oleh Shulman (1987) dan Grossman (1990). Model PCK guru yang diusulkan oleh Magnusson et al. (2002) yaitu dengan mengidentifikasi hubungan antara domain pengetahuan guru meliputi: (1) pengetahuan materi pelajaran (subject matter), substansi maupun sintaknya, (2) pengetahuan pedagogi umum, dan (3) pengetahuan konteks materi, dan sumber-sumber pengetahuan guru (4) pengetahuan konten pedagogi (PCK). Magnusson et al. (2002) berpendapat bahwa pengetahuan materi pelajaran, pengetahuan pedagogi, dan pengetahuan tentang konteks sangat berpengaruh pada PCK yang dipegang oleh guru. Dengan demikian, model ini menunjukkan bahwa pengetahuan mata pelajaran, pengetahuan pedagogi, dan pengetahuan tentang konteks sangat mempengaruhi terbentuknya PCK guru, seperti yang ditunjukkan pada Gambar 1.

Menurut Magnusson et al., (2002) orientasi mengajar adalah pengetahuan dan keyakinan guru tentang maksud dan tujuan mengajarkan materi pada level kelas tertentu. Orientasi pengajar (guru) dinyatakan sebagai peta konsep dalam menentukan tujuan pembelajaran, implementasi materi yang berkaitan dengan kurikulum, dan evaluasi belajar siswa. Berkaitan dengan sistem pendidikan yang berlaku di Indonesia, orientasi mengajar identik dengan pencapaian kompetensi peserta didik, seperti kompetensi inti dan kompetensi dasar dalam kurikulum 2013. Pengetahuan Kurikulum menunjukkan pemahaman guru tentang tujuan dan sasaran belajar siswa dan ruang lingkup serta urutan konsepkonsep ilmiah yang akan diajarkan. Pengetahuan kurikulum guru terdiri dari dua kategori: (a) tujuan kurikulum yang berlaku dan tujuan pembelajaran tiap topik; serta (b) program-program kurikuler tertentu, sumber dan materi.

Model PCK guru yang diusulkan oleh Magnusson, Krajcik, \& Borko (2002) merupakan pengembangan dari model PCK yang telah diusulkan oleh Shulman (1987) dan Grossman (1990). Model PCK guru yang diusulkan oleh Magnusson et al. (2002) yaitu dengan mengidentifikasi hubungan antara domain pengetahuan guru meliputi: (1) pengetahuan materi pelajaran (subject matter), substansi maupun sintaknya, (2) pengetahuan pedagogi umum, dan (3) pengetahuan konteks materi, dan sumber-sumber pengetahuan guru (4) pengetahuan konten pedagogi (PCK). Magnusson et al. (2002) berpendapat bahwa pengetahuan materi pelajaran, pengetahuan pedagogi, dan pengetahuan tentang konteks sangat berpengaruh pada PCK yang dipegang oleh guru. Dengan demikian, model ini menunjukkan bahwa pengetahuan mata pelajaran, pengetahuan pedagogi, dan pengetahuan tentang konteks sangat mempengaruhi terbentuknya PCK guru, seperti yang ditunjukkan pada Gambar 1.

Menurut Magnusson et al., (2002) orientasi mengajar adalah pengetahuan dan keyakinan guru tentang maksud dan tujuan mengajarkan materi pada level kelas tertentu. Orientasi pengajar (guru) dinyatakan sebagai peta konsep dalam menentukan tujuan pembelajaran, implementasi materi yang berkaitan dengan kurikulum, dan evaluasi belajar siswa. Berkaitan dengan sistem pendidikan yang berlaku di Indonesia, orientasi mengajar identik dengan pencapaian kompetensi peserta didik, seperti 
kompetensi inti dan kompetensi dasar dalam kurikulum 2013. Pengetahuan Kurikulum menunjukkan pemahaman guru tentang tujuan dan sasaran belajar siswa dan ruang lingkup serta urutan konsepkonsep ilmiah yang akan diajarkan. Pengetahuan kurikulum guru terdiri dari dua kategori: (a) tujuan kurikulum yang berlaku dan tujuan pembelajaran tiap topik; serta (b) program-program kurikuler tertentu, sumber dan materi.

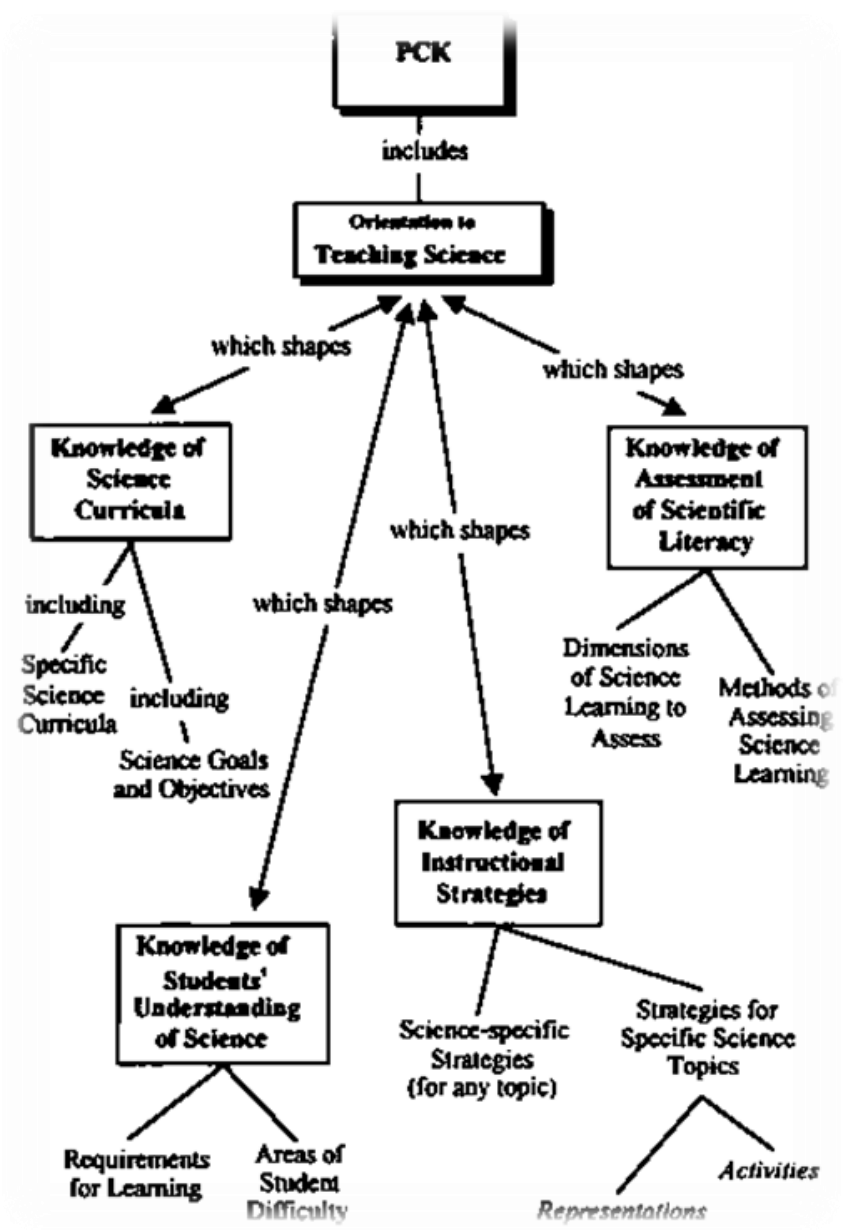

Gambar 1. Model PCK Magnusson (2002) yang memuat orientation to teaching science

Komponen PCK pengetahuan tentang pemahaman siswa terhadap materi mencakup tentang kebutuhan siswa terhadap konsep-konsep materi tertentu dan potensi kesulitan belajar yang mungkin dialami siswa serta kesalahpahaman (miskonsepsi) yang mungkin terjadi ketika belajar konsepkonsep topik bahasan tertentu. Pengetahuan tentang strategi pembelajaran meliputi strategi umum yang biasa digunakan dalam pembelajaran, seperti strategi pembelajaran melalui siklus-siklus pembelajaran dan strategi khusus dalam pembelajaran topik-topik tertentu. Disamping itu juga memuat penjelasan cara merepresentasikan sebuah konsep dengan cara tertentu seperti model diagram, gambar, tabel, dan grafik) serta melibatkan siswa dalam pembelajaran untuk melakukan investigasi, eksperimen, demonstrasi, simulasi, masalah atau contoh. Komponen tentang pengetahuan penilaian, meliputi (a) pengetahuan tentang dimensi pembelajaran IPA yang penting untuk dinilai dan (b) pengetahuan tentang strategi penilaian dan metode belajar siswa yang dapat dinilai (Magnusson et al, 1999). Metode penilaian yang efektif termasuk penilaian informal, formatif dan sumatif yang dilaksanakan untuk mengungkapkan pemahaman siswa terhadap konsep-konsep IPA tertentu. 


\section{METODE}

Penelitian ini menggunakan kaidah-kaidah penelitian deskriptif. Populasi pada penelitian ini adalah semua materi pada buku guru SD yang telah digunakan dalam implementasi kurikulum 2013. Sampel pada penelitian ini adalah beberapa halaman pada buku yang dianalisis, diambil dengan cara acak dengan ukuran sample $20 \%$ dari total halaman dalam buku, dengan mengadopsi cara analisis buku yang pernah dilakukan oleh Chiappetta, E.L, Fillman, D.A, Sethna (1993). Instrumen yang digunakan sebagai alat untuk mengumpulkan data yaitu instrumen evaluasi buku guru yang berisi perpaduan indikator PCK dari lima komponen PCK yang dikembangkan oleh Magnusson et al. dalam Newsome dan Lederman (2002) dan instrumen yang telah dikembangkan Swanepoel (2010). Instrumen evaluasi buku guru berisi kriteria-kriteria tentang konten PCK dalam buku. Pengisian instrumen tersebut dilakukan dengan memberikan nilai antar 0 sampai 3 sesuai rubrik evaluasi. Setiap kriteri dijelaskan dalam rubrik intrumen evaluasi.

Sampel diambil dengan teknik purposive random sampling menyesuaikan karakteristik tema pada buku Tematik SD. Pemilihan sampel dalam penelitian ini dilakukan dengan memilih subtema pada buku Tematik yang akan dianalisis. Identik dengan penelitian yang telah dilakukan Chiappetta, E.L, Fillman, D.A, Sethna (1993) bahwa jumlah halaman yang dianalisis dalam sebuah buku diambil sebanyak $20 \%$ dari seluruh jumlah halaman dan difokuskan pada tema IPA. Tema IPA dipilih berdasarkan indikator PCK dari Magnusson et al. (2002) yang mirip dengan karakteristik pembelajaran IPA. Hal ini diadaptasi dari Journal of research in science teaching (Chiappetta, E.L, Fillman, D.A, Sethna, 1993). Jumlah halaman tersebut ternyata memenuhi untuk satu subtema dari buku Tematik SD kelas V Tema 1 Benda-Benda di Lingkungan Sekitar dengan Subtema Perubahan Wujud Benda (sebagai sampel A) dan kelas VI Tema 1 Selamatkan Makhluk Hidup dengan Subtema Tumbuhan Sumber Kehidupan (sebagai sampel B).

Data yang dikumpulkan dalam penelitian ini adalah data validitas dan reliabilitas instrumen evaluasi buku guru, serta data hasil evaluasi buku guru. Validitas instrumen evaluasi didapatkan dari hasil validasi kepada dua pakar tentang PCK dengan lembar validasi. Reliabilitas instrumen evaluasi dianalisis berdasarkan hasil pengisian instrumen evaluasi buku guru oleh evaluator (guru SD). Pengisian instrumen evaluasi buku guru dilakukan dengan memberikan nilai antar 0 sampai 3 sesuai rubrik evaluasi.

Analisis data dalam penelitian ini dilakukan dengan menghitung prosentase nilai PCK dari hasil instrumen evaluasi. Selain prosentase total nilai PCK, prosentase setiap indikator dari PCK juga dihitung untuk menentukan kuantitas kemunculan indikator tersebut dalam buku guru. Sehingga diharapkan penyempurnaan buku atau hal yang harus dikerjakan guru dalam melengkapinya dapat dilakukan.

\section{HASIL DAN PEMBAHASAN}

\section{Deskripsi Komponen PCK Buku Guru}

Instrumen evaluasi buku guru berisi kriteria-kriteria tentang konten PCK dalam buku. Pengembangan instrumen berisi komponen PCK sampai pada indikatornya masing-masing. Komponen Content Knowledge (CK) dibagi menjadi tiga subkomponen yaitu capaian pembelajaran, pengetahuan inti, dan hakekat ilmu pengetahuan. Sedangkan komponen Pedagogical Knowledge (PK) dibagi menjadi enam subkomponen yaitu kegiatan pembelajaran, penilaian, contoh dan penjelasan, kerangka metakognisi, perbedaan perlakuan siswa, memberi motivasi pada siswa. Penyusunan komponen-komponen ini berdasarkan lima komponen PCK yang dikembangkan oleh Magnusson et 
al., (2002) dan instrumen yang telah dikembangkan Swanepoel (2010). Masing-masing indikator memiliki nilai 0-3 yang ditentukan dengan rubrik penilaian. Selanjutnya instrumen ini dinyatakan valid oleh pakar PCK.

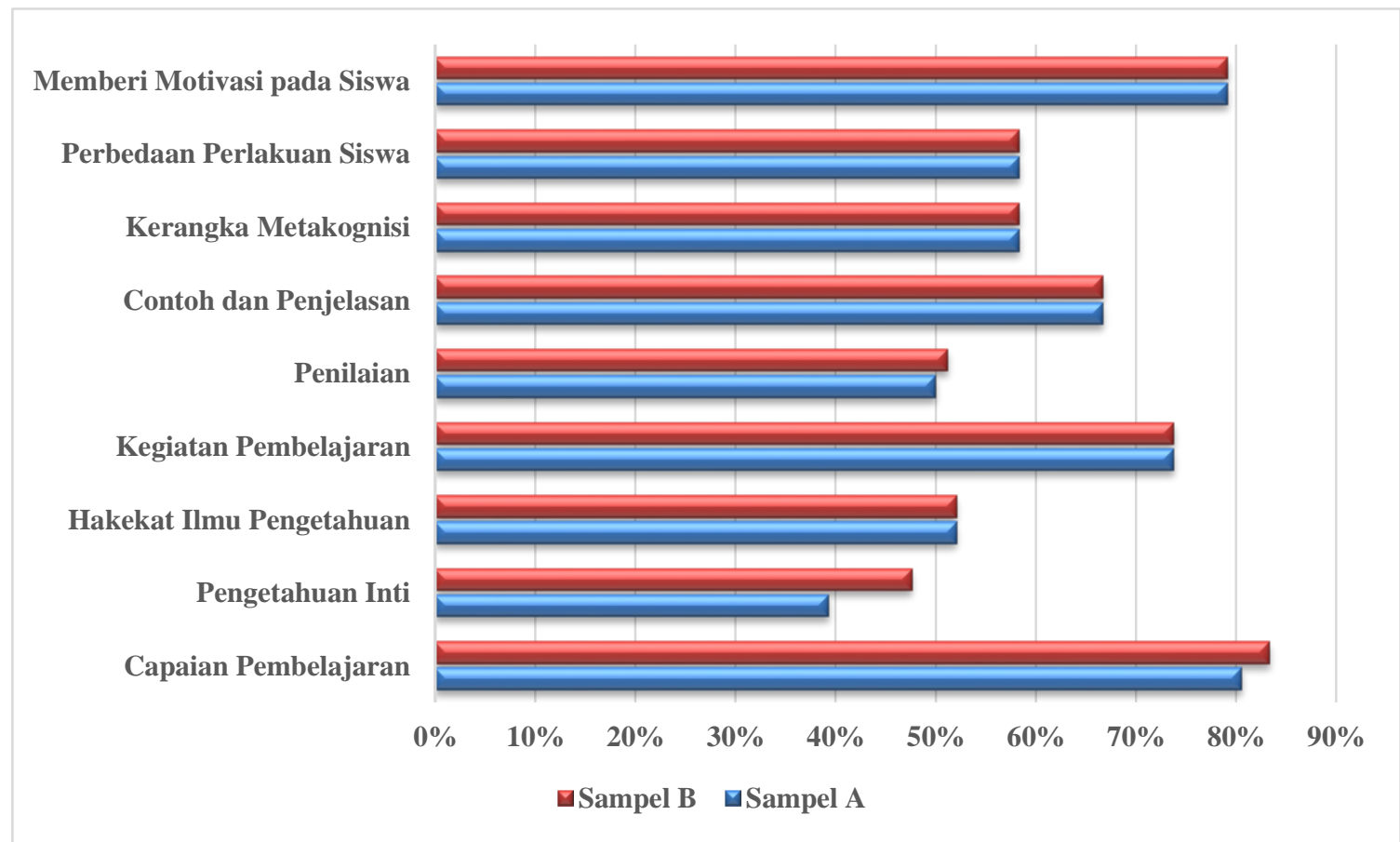

Gambar 2. Hasil evaluasi buku guru SD untuk Sampel A dan Sampel B

Evaluasi terhadap buku guru SD dilakukan oleh empat orang evaluator yang merupakan guruguru dari empat SD yang berbeda di Tulungagung. Tabel 1 menunjukkan rata-rata hasil evaluasi buku guru SD dalam setiap indikator komponen PCK. Sedangkan prosentase muatan PCK dalam buku guru ditunjukkan pada Gambar 2 untuk setiap sub komponennya.

Tabel 1. Rata-Rata Nilai Setiap Indikator Komponen PCK

\begin{tabular}{|c|c|c|c|c|}
\hline $\begin{array}{l}\text { KOMPONEN } \\
\text { PCK } \\
\end{array}$ & $\begin{array}{l}\text { SUB } \\
\text { KOMPONEN }\end{array}$ & INDIKATOR & $\begin{array}{l}\text { NILAI } \\
\text { SAMPEL A }\end{array}$ & $\begin{array}{l}\text { NILAI } \\
\text { SAMPEL B }\end{array}$ \\
\hline \multirow[t]{7}{*}{$\begin{array}{l}\text { CONTENT } \\
\text { KNOWLEDGE }\end{array}$} & \multirow[t]{3}{*}{$\begin{array}{l}\text { Capaian } \\
\text { Pembelajaran }\end{array}$} & $\begin{array}{l}\text { Semua Capaian Pembelajaran } \\
\text { ditampilkan secara menyeluruh }\end{array}$ & 2.75 & 2.75 \\
\hline & & $\begin{array}{l}\text { Capaian Pembelajaran } \\
\text { dibobotkan dengan } \\
\text { tepat }\end{array}$ & 2.25 & 2.5 \\
\hline & & $\begin{array}{l}\text { Capaian Pembelajaran } \\
\text { dinyatakan dengan } \\
\text { jelas }\end{array}$ & 2.25 & 2.25 \\
\hline & \multirow[t]{4}{*}{$\begin{array}{l}\text { Pengetahuan } \\
\text { Inti }\end{array}$} & $\begin{array}{l}\text { Semua pengetahuan } \\
\text { inti ditunjukkan }\end{array}$ & 1.75 & 2.25 \\
\hline & & $\begin{array}{l}\text { Pengetahuan awal } \\
\text { disebutkan }\end{array}$ & 1 & 1.75 \\
\hline & & $\begin{array}{l}\text { Menunjukkan } \\
\text { miskonsepsi yang } \\
\text { sering terjadi }\end{array}$ & 0 & 0 \\
\hline & & Keruntutan konsep & 1.25 & 1.75 \\
\hline
\end{tabular}




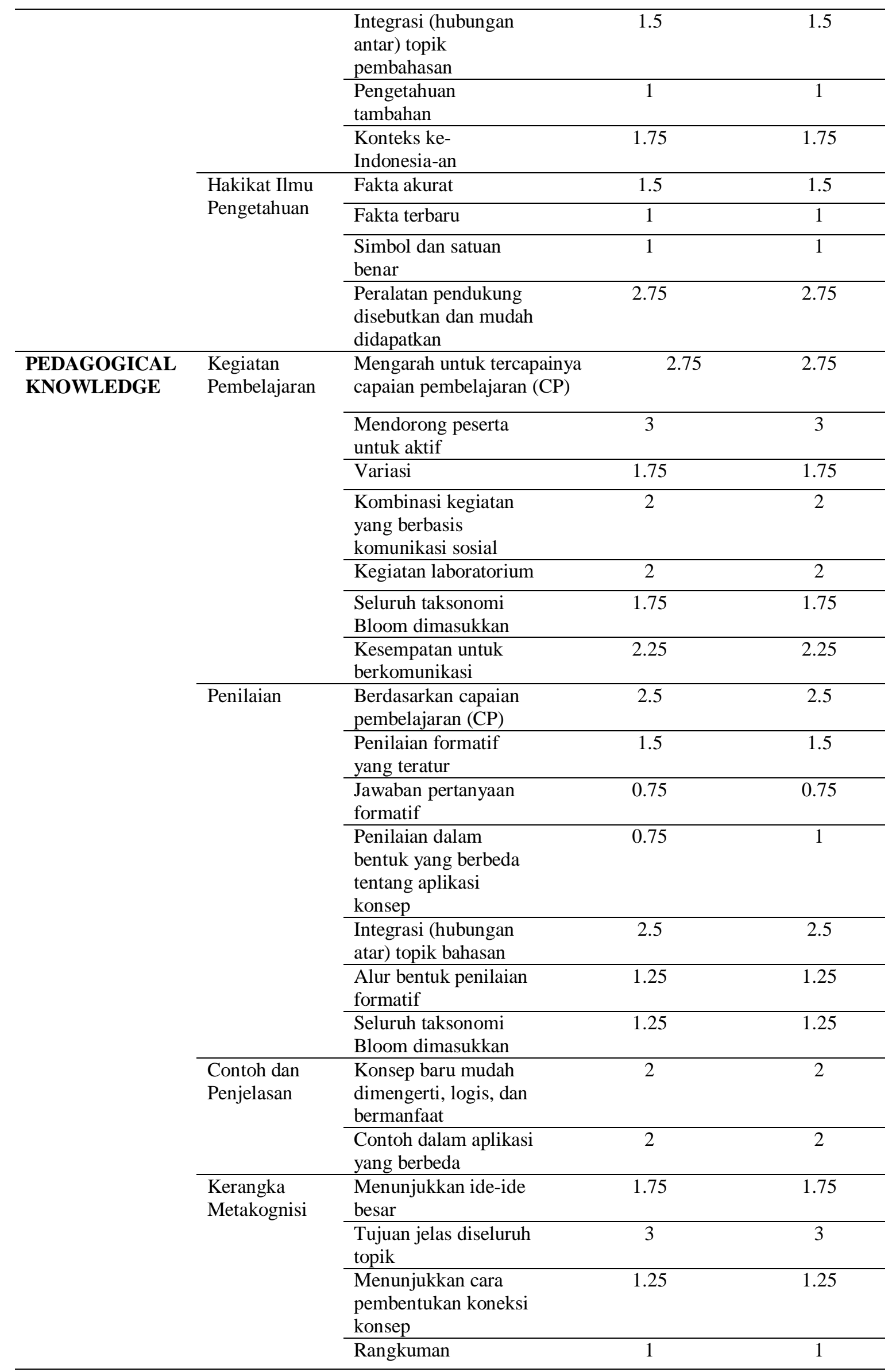




\begin{tabular}{llcc}
\hline $\begin{array}{l}\text { Perbedaan } \\
\text { Perlakuan } \\
\text { Siswa }\end{array}$ & $\begin{array}{l}\text { Memenuhi } \\
\text { kemampuan siswa }\end{array}$ & 1.75 & 1.75 \\
\hline Memberi & $\begin{array}{l}\text { Contoh bervariasi } \\
\text { Motivasi pada }\end{array}$ & & \\
Siswa & $\begin{array}{l}\text { yang berpusat pada } \\
\text { siswa }\end{array}$ & 2.75 & 2.75 \\
\cline { 2 - 3 } & $\begin{array}{l}\text { Keterkaitan konsep } \\
\text { dengan kehidupan } \\
\text { sehari-hari } \\
\text { ditunjukkan }\end{array}$ & 2 & 2 \\
& & & \\
\hline
\end{tabular}

\section{Pembahasan}

Instrumen evaluasi buku yang telah diadaptasi, selanjutnya diaplikasikan oleh empat guru SD dari sekolah yang berbeda sebagai evaluator. Masing-masing sekolah adalah SDN Bago 1, SDN Jepun 1, SDN Kepatihan 3, dan SDN Kampungdalem 6. Semua guru tersebut mempunyai kualifikasi sangat bagus, karena sudah berpengalaman dalam bidang pembelajaran dan pembimbingan olimpiade tingkat SD. Para guru diberikan instrumen evaluasi beserta rubriknya dan dua sampel buku guru SD. Masingmasing adalah buku Tematik SD kelas V Tema 1 Benda-Benda di Lingkungan Sekitar dengan Subtema Perubahan Wujud Benda (sebagai sampel A) dan kelas VI Tema 1 Selamatkan Makhluk Hidup dengan Subtema Tumbuhan Sumber Kehidupan (sebagai sampel B).

Para guru tidak diberikan pelatihan khusus dalam penggunaan instrumen evaluasi. Mereka hanya menerima penjelasan singkat tentang cara pengisian instrumen dengan melihat rubrik sebagai panduannya. Masing-masing indikator terisi oleh nilai yang diberikan guru. Peneliti memberika waktu sehari untuk mempelajari dan mengisi instrumen evaluasi buku guru SD tersebut. Mereka tidak kesulitan dalam melakukan evaluasi dan memahami setiap indikator dalam instrumen karena sudah sangat berpengalaman dalam pendidikan sekolah dasar.

Hasil evaluasi dari masing-masing guru ditabulasi dalam lembar kerja analisis data. Masingmasing dihitung rata-rata nilai dari setiap indikator seperti yang ditunjukkan pada Tabel 1. Selanjutnya, nilai setiap indikator dijumlahkan dalam setiap sub komponen PCK dan dihitung prosentase muatan dari poin maksimum setiap sub komonennya yang ada dalam buku guru. Prosentase tersebut ditunjukkan dalam Gambar 2. Berdasarkan gambar tersebut dapat diketahui kisaran rata-rata prosentase masing-masing sub komponen PCK yaitu capaian pembelajaran $82 \%$, pengetahuan inti $44 \%$, hakekat ilmu pengetahuan 52\%, kegiatan pembelajaran $74 \%$, penilaian $50 \%$, contoh dan penjelasan $67 \%$, kerangka metakognisi $58 \%$, perbedaan perlakuan siswa $58 \%$, serta pemberian motivasi pada siswa $79 \%$. Terdapat prosentase yang cukup rendah dari masing-masing sub komponen PCK dalam buku guru SD.

Berdasarkan data pada Gambar 2, buku guru SD hanya sedikit muatan komponen Content Knowledge terutama pengetahuan inti dan hakekat ilmu pengetahuan. Secara lebih jelas dapat dilihat dalam Tabel 1 sesuai indikator masing-masing. Indikator miskonsepsi memperoleh nilai nol yang artinya belum termuat dalam buku guru. Seharusnya ada pengetahuan tentang miskonsepsi pada buku guru SD karena guru harus terhindar dari miskonsepsi (Warren, 2002) agar terbentuk konsep yang kuat pada siswa. Hal ini harus menjadi perhatian karena miskonsepsi pada guru dapat menyebabkan terjadinya miskonsepsi pada siswa (Narjaikaew, 2013). Apabila guru masih mengalami miskonsepsi, maka rantai miskonsepsi pada siswa akan sulit untuk diputus. Selain pengetahuan miskonsepsi, buku juga perlu ditambah muatan pengetahuan tambahan dan pengetahuan awal sebagai penghubung konsep inti dengan perkembangan ilmu pengetahuan.

Komponen Pedagogical Knowledge juga memiliki beberapa sub komponen yang belum maksimal termuat dalam buku guru SD. Sub komponen tersebut diantaranya adalah penilaian, 
perlakuan pada siswa, dan kerangka metakognisi. Berdasarkan Tabel 1, indikator penilaian lemah dalam hal ketersediaan jawaban tes formatif dan alur soal tes formatif. Artinya soal belum berjenjang berdasarkan tingkat kesulitan dan belum tersedianya jawaban soal tersebut. Sedangkan siswa yang mempunyai daya tangkap lebih terhadap materi masih cenderung diperlakukan sama dengan yang tertinggal, terutama mengenai tingkat keluasan maupun kedalaman materi yang diberikan. Indikator dalam sub komponen kerangka metakognisi masih lemah dalam hal membuat koneksi antar konsep. Hal ini perlu diperhatikan agar siswa dapat mendapatkan kerangka konseptual yang utuh sebagai bangunan keilmuan.

Wawancara terstuktur dilakukan pada dua dari empat guru tersebut untuk klarifikasi hasil pengisian instrumen evaluasi buku guru SD. Hasilnya, persepsi guru tentang setiap indikator dalam intrumen sudah sesuai dan sama sehingga tidak akan berdampak pada bias data. Guru juga menyampaikan bahwa buku guru SD kurikulum 2013 tidak sepenuhnya dapat digunakan sebagai pegangan guru, artinya harus ditambah dengan buku penunjang lain untuk melengkapi, terutama dalam hal Content Knowledge.

\section{SIMPULAN DAN SARAN}

\section{Simpulan}

Berdasarkan rumusan masalah dan hasil penelitian dapat disimpulkan bahwa intrumen evaluasi buku guru SD dapat digunakan untuk menentukan muatan PCK dalam buku. Hal ini diperlukan untuk memilih buku yang relevan menjadi pegangan guru karena harus memuat Pedagogical Knowledge dan Content Knowledge. Rata-rata prosentase masing-masing sub komponen PCK dalam buku guru SD kurikulum 2013 yaitu capaian pembelajaran 82\%, pengetahuan inti 44\%, hakekat ilmu pengetahuan $52 \%$, kegiatan pembelajaran $74 \%$, penilaian $50 \%$, contoh dan penjelasan $67 \%$, kerangka metakognisi $58 \%$, perbedaan perlakuan siswa $58 \%$, serta pemberian motivasi pada siswa $79 \%$.

\section{Saran}

Sub komponen Content Knowledge perlu dilengkapi tentang pengetahuan miskonsepsi dan pengetahuan tambahan. Sedangkan sub komponen Pedagogical Knowledge perlu dilengkapi tentang kelengkapan penilaian dan kerangka metakognisi. Beberapa hal tersebut hendaknya ditindaklanjuti oleh pengguna buku, khususnya guru untuk melengkapi ketika melaksanakann pembelajaran dan menjadikan pertimbangan untuk penelitian lanjutan.

\section{DAFTAR PUSTAKA}

Chiappetta, E.L, Fillman, D.A, Sethna, G. H. (1993). Do Middle School Life Science Textbooks Provide a Balance of Scientific Literacy Themes? Journal of Research in Science Teaching, 30(2), 787-797.

Cochran, K. F. (1993). Pedagogical Content Knowing: An Integrative Model for Teacher Preparation. Journal of Teacher Education, 44(4), 263-272.

Fensham, P. J. (2008). Science Education Policy-Making: Eleven emerging issues. Paris: UNESCO Publishing.

Loughran, J., Berry, A., \& Mulhall, P. (2012). Understanding and Developing Science Teachers ' Pedagogical Content Knowledge (2nd ed.). Rotterdam: Sense Publishers.

Magnusson, S., Krajcik, J., \& Borko, H. (2002). Nature, Sources, and Development of Pedagogical 
Content Knowledge for Science Teaching. In J. Gess-Newsome \& N. G. Lederman (Eds.), Examining Pedagogical Content Knowledge (pp. 95-132). New York: Kluwer Academic Publishers.

Mishra, P., \& Koehler, M. (2009). Teachers' Technological Pedagogical Content Knowledge and Learning Activity Types : Curriculum-based Technology Integration Reframed. Journal of Research on Technology in Education, 41(4), 393-416.

Narjaikaew, P. (2013). Alternative Conceptions of Primary School Teachers of Science about Force and Motion. Procedia - Social and Behavioral Sciences, 88, 250-257. http://doi.org/10.1016/j.sbspro.2013.08.503

Shulman, L. S. (1986). Those Who Understand: Knowledge Growth in Teaching. Educational Researcher, 15(2), 4-14.

Shulman, L. S. (1987). Knowledge and Teaching: Foundations of the New Reform. Harvard Educational Review, 57(1), 1-21.

Swanepoel, S. (2010). The assessment of the quality of science education textbooks: Conceptual framework and instruments for analysis. University of South Africa.

Turnuklu, E. B., \& Yesildere, S. (2007). IUMPST: The Journal, Vol 1 (Content Knowledge), October 2007. IUMPST: The Journal, 1 (October), 1-13.

Warren, J. (2002). Reflecting on a misconception. The Science Teacher, 69 (2), 24-33.

Williams, J., \& Lockley, J. (2012). Using CoRes to Develop the Pedagogical Content Knowledge ( PCK ) of Early Career Science and Technology Teachers. Journal of Technology Education, 24 (1), 34-53. 